\title{
El flâneur y el mestizo latinoamericano como paradigmas de sujetidad barroca
}

\section{[The Flâneur and the Latin American Mestizo as Baroque Sujetity Paradigms]}

\author{
EDWIN ALCARÁs \\ Facultad Latinoamericana de Ciencias Sociales, Ecuador \\ ealcaras@gmail.com
}

\begin{abstract}
Resumen: Este artículo explora las figuras del flâneur (Walter Benjamin) y del "mestizo" (Bolívar Echeverría). Reúno con el sustantivo "mestizo" una serie de operaciones estilísticas y retóricas que emplea Echeverría para describir el mestizaje como fenómeno histórico de las sociedades urbanas en las colonias españolas en los siglos XVI y XVII. Partiré de la lectura de Echeverría a Benjamin de principios de los años noventa. Luego analizaré la figura del flâneur y la del mestizo para mostrar algunas líneas de conexión, desde la estrategia alegórica a la relación entre el barroco y la sociedad moderna. Por último, consideraré ambas figuras como paradigmas (Agamben 2010a) de sujetidad barroca, es decir, como principios de inteligibilidad de formas sociales que resisten las contradicciones de la modernidad capitalista.

Palabras clave: Walter Benjamin, Bolívar Echeverría, mestizaje, Giorgio Agamben, alegoría
\end{abstract}

\begin{abstract}
This article explores two figures: the flâneur (Walter Benjamin) and the "mestizo" (Bolívar Echeverría). Under the word "mestizo" I gather a group of stylistic and rhetorical operations that Echeverría uses to describe mestizaje as a historical phenomenon occurred in the urban societies of Spanish Colonies during the 16th and 17th centuries. I start with a historical approach to Echeverría's readings of Benjamin from the beginning of the 1990s. Then I show some possible connections between both figures, from the allegorical strategy to the relationship between baroque and modern society. Finally, I conceive them as paradigms (Agamben 2010a) of baroque sujetity; that is, principles of intelligibility of social forms that resist the contradictions of Western modern capitalism.
\end{abstract}

Key words: Walter Benjamin, Bolívar Echeverría, mestizaje, Giorgio Agamben, allegory

\section{Echeverría lector de Benjamin}

Contra la primera impresión que suscita un vistazo al conjunto de las obras de Bolívar Echeverría y de Walter Benjamin, el núcleo del interés del filósofo latinoamericano por el autor de El origen del drama barroco alemán (Trauerspiel) no se produjo a partir de la noción de barroco, ni de su categoría principal, la alegoría. Llama la atención que Echeverría 
(conocido en el mundo por sus trabajos sobre el barroco como clave "heurística" de la modernidad latinoamericana) no se refiera $-\mathrm{y}$ ni siquiera cite- el largo ensayo en el que Benjamin interpretó el barroco como un modo alternativo de concebir la modernidad capitalista, como sugiere Chiampi 2000 (pp. 90 y ss.).

Según la cronología de sus trabajos publicados, parece ser que Echeverría no empieza a escribir sobre Benjamin sino hasta los primeros años de la década de los noventa, cuando trabajaba la relación entre modernidad y barroco. En 1991 participó en un proyecto de investigación titulado "El mestizaje cultural y la cultura barroca en América Latina" y, entre ese año y el siguiente, dirigió el proyecto "Modernidad europea, mestizaje cultural y ethos barroco", ambos en la Universidad Nacional Autónoma de México (UNAM), donde era profesor titular.

Los ensayos del primer libro de Echeverría, El discurso crítico de Marx (1986), se redactaron entre 1974 y 1980. En la nota introductoria, el autor reconoce su deuda con la tradición de los "marxismos marginales" que han permanecido fieles al espíritu revolucionario primigenio de Marx. Curiosamente, no se menciona a Benjamin, aunque en 1971 Echeverría había traducido el texto El autor como productor para la revista mexicana Siempre!

Entre 1981 y 1982 Echeverría impartió un curso famoso en la UNAM sobre El Capital de Karl Marx, que mucho más tarde reelaboró y publicó bajo el título de Definición de la cultura (2001). No aparece allí ninguna referencia a Benjamin. Poco tiempo después, en el ensayo "La 'forma natural' de la reproducción social" (1984), Echeverría menciona de manera breve e indirecta una idea Benjamin acerca del lenguaje: "La insistencia actual en la idea de que el significar humano no es sólo comunicación/interpretación de mensajes, sino siempre historia de sí mismo, proviene, formulada en términos místicos, de W. Benjamin".

En el periodo entre 1991 y 1992 aparecieron, como resultado del proyecto "Modernidad europea, mestizaje cultural y ethos barroco", los libros Conversaciones sobre lo barroco (1993) y Las ilusiones de la modernidad (1995), en cuyo capítulo cuarto, "La identidad evanescente", el autor amplía también de forma breve la misma idea de Benjamin sobre la historicidad del lenguaje. Dice Echeverría:

En el ensayo de Walter Benjamin Sobre el lenguaje en general y el lenguaje humano domina una idea que ha demostrado ser central en la historia del pensamiento del siglo xx y sin la cual la aproximación social y semiótica al problema de la identidad quedaría incompleta: en el caso del ser humano, 
éste no sólo habla con la lengua, se sirve de ella como instrumento, sino, sobre todo, habla en la lengua. (Echeverría 1997 [1995], p. 60)

En 1994 aparecen, casi de modo simultáneo, varios trabajos que presentan el núcleo de lo que, según Oliva Mendoza 2013, constituyen las dos preocupaciones fundamentales del proyecto filosófico de Echeverría, a saber, la reconceptualización de la utopía como horizonte político y la exploración del barroco como un experimento histórico de modernidad alternativa. Según Oliva Mendoza:

Por una parte [Echeverría] encuentra, especialmente en Benjamin, una reformulación del problema de la utopía revolucionaria que se deduce de la teoría de Lukács, a través del problema de la teología y el mesianismo; por la otra, estudia modos civilizatorios matrices que subsisten dentro de la modernidad capitalista; de estos modos, se interesa especialmente por la configuración barroca dentro del capitalismo. (Oliva Mendoza 2013, p. 178)

En efecto, durante estos años se percibe un empeño del filósofo por repensar el concepto de revolución y sus fundamentos teóricos con el fin de trascender el llamado socialismo real, cuyo colapso se anunciaba como el fin de la historia. Por otro lado, Echeverría también trabajaba en una interpretación filosófico-histórica de un posible proyecto -fallido, como él mismo reconoce- sobre una modernidad alternativa, distinta a la efectivamente impuesta; es decir, de una modernidad sudeuropea, católica y barroca. Pueden mencionarse dos trabajos a modo de ejemplo de esta incipiente condición doble de la reflexión echeverriana: el ensayo "El ethos barroco" (1996), que apareció en el volumen colectivo Modernidad, mestizaje cultural, ethos barroco, y la conferencia "Benjamin, mesianismo y utopía", pronunciada en septiembre de ese mismo año en el seminario "Los intelectuales y los dilemas políticos del siglo xx", que más tarde se publicó como capítulo del libro Valor de uso y utopía (1998).

Si se tiene en cuenta el libro Conversaciones sobre lo barroco, publicado un año antes de estos trabajos (y que consiste en una transcripción de las conversaciones que el autor sostuvo con el profesor alemán Horst Kurnitzky y algunos de sus colegas y estudiantes de la UNAM), se podría pensar que la preocupación por el barroco del profesor Echeverría es anterior a sus trabajos sobre Benjamin, un aspecto que me interesará resaltar más adelante. 
En los años siguientes, entre 1994 y 1997, Echeverría coordinó el proyecto de investigación "El concepto de cultura política y la vida política en América Latina", cuyos resultados se recogieron en dos libros publicados en 1998, a saber, Valor de uso y utopía y La modernidad de lo barroco. En el primero se incluye el ensayo "Deambular: el flâneur y el 'valor de uso'", en el que Echeverría recupera la conexión entre esa figura benjaminiana y las posibilidades de resistencia frente al impulso homogeneizador de la modernidad. Resulta curioso que, ni en ese trabajo ni en "Benjamin: mesianismo y utopía", publicado por primera vez en forma de texto, Echeverría examine la noción de "alegoría", fundamental para entender el fundamento "ontológico" de la flânerie y que se relaciona de manera profunda con el concepto benjaminiano de barroco. El profesor ecuatoriano pasa muy por encima del sentido alegórico del flâneur y ni siquiera nombra la relación entre éste y el Trauerspiel o drama barroco alemán. Por otro lado, en sus trabajos específicamente dedicados al barroco, Echeverría nunca se refiere a la constitución alegórica de un "sujeto barroco" que Benjamin sugirió para describir una suerte de estrategia de supervivencia frente a la subsunción del valor de uso por el valor abstracto de la mercancía.

\subsection{El lugar de Benjamin en la obra de Echeverría}

Echeverría leyó con intensidad a Benjamin por más de más de tres décadas. Varias fuentes (Sigüenza 2011; Sánchez Prado 2010) suponen que habría entrado en contacto con el pensamiento del alemán durante sus estudios en la Universidad Libre de Berlín (1965-1967), en los seminarios de Jacob Taubes y Peter Szondi. Desde entonces y hasta el final de su vida, nunca dejó de sentir interés por la obra de Benjamin. De hecho, el último curso que ofreció en la UNAM en 2010 se enfocó en la relación entre Benjamin y las vanguardias artísticas de principios del siglo $\mathrm{xx}$.

La primera intervención en el debate público en la que Echeverría se ocupa de Benjamin ("Benjamin: mesianismo y utopía", 1998) busca rearticular el "gesto" mesiánico de Benjamin en el marco de la crisis de los lenguajes políticos de fines del siglo Xx a través de una lectura original del volumen póstumo Tesis sobre la historia. Resulta muy extraño que, aunque Echeverría conocía bien la obra de Benjamin, no sólo nunca trabaja, sino que ni siquiera considera la categoría de Trauerspiel, lo cual podría haber sido "natural" si se tiene en cuenta que en esos años Echeverría desarrollaba justo su teoría sobre el barroco. Dado el amplio conocimiento que tenía sobre la obra de Benjamin y el interés filosófico que mostraba en los conceptos asociados al barroquismo como

Revista de Filosofía Diánoia, vol. 65, no. 85 (noviembre de 2020-abril de 2021) e-ISSN: 1870-4913 • DOI: https://doi.org/10.22201/iifs.18704913e.2020.85.1776 
clave hermenéutica de la realidad latinoamericana, parecería bastante improbable que no hubiera conocido los conceptos de alegoría y barroco que Benjamin trabaja en forma minuciosa en varios capítulos de $E l$ origen del Trauerspiel. Lo que Echeverría recupera de Benjamin son las categorías de "mesianismo" y "teología" que aparecen mucho más en el pensamiento del autor alemán, en la década de los treinta.

En opinión de Sánchez Prado 2010, la relación entre Echeverría y Benjamin se enmarca en el gran propósito filosófico del profesor ecuatoriano de buscar una "nueva ontología política" para hacer frente al vaciamiento de sentido de las prácticas políticas hacia fines del siglo XX que, según Sánchez Prado, se debía al desgaste del marco "ontológico" de la esfera política tradicional y de sus experimentos históricos:

Por lo tanto, para adoptar la dimensión social-natural de la política que, en opinión de Echeverría, está borrada por el privilegio del valor, se necesita una nueva ontología política, una que sea capaz de mover lo político más allá del horizonte del capital sin abandonar plenamente los legados críticos del pasado. Las Tesis de Benjamin cumplen bien esta función porque, como veremos en un momento, su extemporaneidad les permite despertar (o rescatar, para ser más precisos) elementos latentes de la historia social-natural e inscribirlos en una nueva ontología política. (Sánchez Prado 2010, p. 47; a menos que se indique lo contrario, las traducciones son mías)

Para Sánchez Prado, la tarea de buscar o imaginar esta nueva ontología englobaría tanto la reflexión sobre la utopía revolucionaria (relacionada con el mesianismo) como la caracterización filosófica del barroco, pues ambas tratan de recuperar una dimensión política, práctica y transformadora para la modernidad tardía y, al mismo tiempo, las dos trascienden los límites "ontológicos" de la política entendida como un ámbito de reflexión de la libertad humana. Para ambos aspectos el pensamiento de Benjamin fue fundamental para Echeverría, pues le proporcionó elementos para trabajar tanto la categoría de utopía como la de barroco. Sigue Sánchez Prado:

Más que prescribir un paisaje utópico, el propósito de Echeverría de construir una ontología de la modernidad realmente existente contiene el potencial alegórico del barroco, lo cual le permite defender una teoría de la modernidad que, siguiendo a Leibniz, "combina una teoría filosófica con la sabiduría hermenéutica". Es decir que la teoría de Echeverría da cuenta de la naturaleza ontológica del capitalismo junto con los compromisos epistemológicos de la subjetividad con el capital y la mercancía. A través de

Revista de Filosofía Diánoia, vol. 65, no. 85 (noviembre de 2020-abril de 2021) e-ISSN: 1870-4913 • DOI: https://doi.org/10.22201/iifs.18704913e.2020.85.1776 
su definición del "ethos histórico" como "un principio de construcción del mundo de la vida", y entendiendo el barroco como uno de los cuatro "principios de construcción" en el terreno de la modernidad capitalista, Echeverría emplea la idea del barroco como una formación estética de la historia cultural con el fin de negociar lo ontológico junto con lo hermenéutico. (Sánchez Prado 2010, p. 52)

Pese a que Echeverría no cita a Benjamin en sus trabajos sobre el barroco, o que lo cita sólo en forma velada como sugiere un trabajo reciente (Campuzano 2020), Sánchez Prado establece una conexión teórica entre la noción de ethos barroco echeverriano y al menos dos conceptos de Benjamin: el primero en relación con la "alegoría de la mercancía", que Benjamin trabajó sobre todo en sus últimos trabajos y que, por lo demás, se conecta con la caracterización del flâneur y, el segundo, respecto de la "voluntad de forma", a través de la cual el sujeto social configura su mundo de la vida y constituye el contenido de su reproducción social específica y concreta. Cito de nuevo a Sánchez Prado:

De modo que, en el pensamiento de Echeverría, la forma barroca finalmente se convierte en un ethos con un gran potencial para superar la modernidad capitalista desde dentro en dos aspectos. Primero, preserva la dimensión social-natural del valor de uso en su alegoría de la mercancía. Además, siguiendo la terminología de los "vencidos" que emplea Benjamin en sus Tesis y adopta deliberadamente aquí Echeverría, su "voluntad de forma" permite la preservación y redención potencial de las dimensiones de la vida y la historia más allá de las formaciones hegemónicas. (Sánchez Prado 2010, p. 53)

Sin embargo, aunque la noción de voluntad de forma aparece en varios de los trabajos de Echeverría sobre el barroco, en ninguno de ellos, como afirma Sánchez Prado, el filósofo ecuatoriano reconoció abiertamente que ésta procediera de Benjamin. Tampoco emprendió nunca una revisión del concepto de alegoría, presente en obras como El origen del Trauerspiel (1928), Sobre algunos temas en Baudelaire (1939) y el póstumo Libro de los pasajes (2005).

El reconocimiento directo de Benjamin sólo asoma, como hemos visto, después de la participación de Echeverría en los proyectos de investigación de la UNAM sobre el barroco, y aun en esos casos el interés de Echeverría se centra en los estudios benjaminianos sobre la cultura y política como materiales para su siguiente proyecto de investigación: "El concepto de cultura política y la vida política en América Latina" (1994-1997).

Revista de Filosofía Diánoia, vol. 65, no. 85 (noviembre de 2020-abril de 2021) e-ISSN: 1870-4913 • DOI: https://doi.org/10.22201/iifs.18704913e.2020.85.1776 


\subsection{De barroco a barroco, la alegoría}

Una de las mayores semejanzas entre los proyectos filosóficos de Benjamin y Echeverría es que ambos se desarrollaron en tiempos de profunda desesperanza política ante un escenario internacional en el que habían triunfado los enemigos de la "utopía" anhelada por el materialismo histórico. En ese contexto adverso (en ese "momento de peligro", como exclama Benjamin 2008) ambos proyectos proponen además una lectura anómala de la tradición filosófica a la que pertenecen. Su originalidad radical en el plano de los conceptos se corresponde en lo político con el gesto desesperado de los "vencidos", de aquellos que tratan de reivindicar el potencial revolucionario que subsiste perfectamente y que es mucho más necesario que nunca.

Echeverría identifica en el autor de Tesis sobre la historia "una capacidad desbordada de irradiar sugerencias" políticas que permanecen fieles al espíritu crítico primigenio de Marx. Para él, Benjamin logró mantener despierta la llama de beligerancia y creatividad que constituyó el germen teórico de los primeros trabajos filosóficos de Marx. La necesidad de ese espíritu crítico — de ese momento negativo, como lo llama Echeverría en varios ensayos- se percibía como urgente a principios de los años noventa del siglo pasado. No sobra recordar que en 1992 - es decir, dos años antes de la primera conferencia de Echeverría sobre Benjamin- se había publicado El fin de la historia y el último hombre de Francis Fukuyama, obra en que se decretaba el final de la historia y se despachaba el materialismo histórico como un experimento fallido. Frente a esto, Echeverría afirma en Las ilusiones de la modernidad:

[E]l cinismo de la política económica contemporánea [...] sólo puede comprenderse a partir de un estado de cosas político más general que, para decirlo de una manera concisa podría llamarse el estado de agotamiento de la cultura política moderna, aquel fenómeno tan mentado en el caso de las regresiones fundamentalistas en los países occidentalizados del Tercer Mundo, al que A. Touraine, reconociéndolo también en Europa, ha descrito como una "desaparición de los lenguajes políticos, de los debates en el campo político y casi del sistema político en cuanto tal". (Echeverría 1997 [1995], p. 41; cursivas y comillas del original)

Este "agotamiento" se relacionaba en forma directa con el hecho de que la política neoliberal se había instalado como una realidad histórica "triunfante" y, por lo tanto, aquello que se hallaba en disputa no era sólo la lucha por la resistencia frente a la modernidad capitalista, sino la posibilidad misma de inteligibilidad de las categorías de "utopía" y 
"revolución" como horizontes de pensamiento y acción política. En este sentido, el pensador ecuatoriano empleó la "inactualidad" de Benjamin como una estrategia para, por una parte, admitir la contingencia del fundamento de cierto marxismo supuestamente superado y, por otra, mantener viva la potencia crítica del materialismo histórico.

Para Echeverría trabajar la historia política a contrapelo — desde el punto de vista de los "vencidos"- resulta extremadamente útil para reelaborar una postura crítica a partir de materiales y elementos desechados por la historia oficial. Echeverría reconoce este mecanismo teórico cuando dice: "en esos trabajos de factura inusitada, Benjamin pensaba introducir un nuevo tipo de discurso reflexivo, hecho de una red de articulaciones entre fragmentos del habla de 'la cosa misma', cuyo tejedor se jugaría por entero en el empeño creativo de selección y combinación" (Echeverría 2005 [1994], p. 10). Si se riza el rizo, podría pensarse que, con sus trabajos sobre el ethos barroco, también Echeverría trataba de crear un lugar en el discurso reflexivo que posibilitara una lectura a contrapelo de la historia de América Latina desde una reapropiación filosófica que rompía, al tiempo que continuaba, con la tradición del materialismo histórico como sistema filosófico, o sea como una herramienta de interpretar - pero sobre todo de transformar- lo real.

Echeverría se apropió de las ideas de Benjamin a través de, como él decía, una "devoración" de sus códigos filosóficos. Al igual que el pensador alemán, Echeverría introduce elementos ajenos al marxismo clásico, como la semiótica y la lingüística, para poner en crisis los alcances del materialismo histórico y obligarlo a ir más allá de sí mismo. A través de ese juego de apropiaciones y crisis ("codigofagias"), modificó algunas ideas de Benjamin para elaborar una ontología de la modernidad capitalista desde un punto de vista latinoamericano. En ese sentido, Sánchez Prado sostiene lo siguiente:

De esta manera, Echeverría construye un Benjamin fuertemente inscrito en su propia versión de la modernidad: barroco en su lenguaje alegórico, implacablemente secular y comprometido con la tarea de defender la utopía socialista. A través de esta redefinición, Echeverría se apropia de Benjamin para comprender la modernidad barroca que busca un nuevo espacio para la política. (Sánchez Prado 2010, p. 44)

El ecuatoriano asimiló el "método" de Benjamin para iluminar un instante de peligro real producto del ascenso triunfante del neoliberalismo como doctrina "verdadera" de la política. Como Benjamin, Echeverría 
combina la teoría materialista con nociones de semiótica, teoría de la literatura, hermenéutica y filosofía del lenguaje como estrategia para mantener vivo el espíritu crítico de Marx a través de la mirada de los vencidos. Por ello dirá Oliva Mendoza que ambos autores formulan "un discurso hermenéutico en una variante materialista [...], cuya importancia para el materialista histórico y dialéctico consiste en rescatar las mónadas del discurso histórico y describir su poder revolucionario" (Oliva Mendoza 2013, p. 23).

\section{Flânerie y alegoría}

\subsection{El flâneur}

Benjamin trabajó con habilidad sorprendente una diversidad de géneros y registros literarios ajenos, en apariencia, a los que se consideraban "propiamente" filosóficos en su tiempo. Uno de ellos fue el de la crítica literaria, que cultivó con especial dedicación, pues tenía la intención de hacer "una contribución a la sociología de la lírica", como apunta José Manuel Cuesta Abad (Benjamin 2014, p. 7).

Estas incursiones en la teoría literaria y las ciencias obedecen, de acuerdo con Buck-Morss 1995 (p. 72), a la intención de Benjamin de "reconstruir el material histórico como filosofía", es decir, de someter sus "materiales" a una tensión dialéctica entre una reconstrucción histórica de la filosofía y una reconstrucción filosófica de la historia. Este tipo de discurso al mismo tiempo filosófico, crítico, histórico y sociológico es el que engendra la noción de flâneur y lo modela como una clave filosófica que descifra el papel del artista moderno en la sociedad "altocapitalista" europea.

La noción de flâneur no está definida con conceptos claros y distintos en la obra de Benjamin. Más bien surge como el resultado narrativo de una serie de observaciones sociológicas, históricas o "fisiológicas" (en el sentido de las fisiologías urbanas populares en Francia, en el siglo XIX) que se sustentan en sus estudios sobre el poeta Charles Baudelaire.

Cuesta Abad (en Benjamin 2014, p. 5) sospecha que el interés de Benjamin en Baudelaire comenzó a partir de su traducción al alemán en 1923 de los Cuadros parisinos (Tableaux parisiens). Poco después, en 1927, Benjamin esbozó el plan de la obra "Los pasajes de París. Una fantasmagoría dialéctica", en el cual propone aplicar su "método" de lectura "sociológica" para desentrañar "la construcción filosófico-histórica de la época moderna en la fase de apogeo del capitalismo industrial". En 
1935, durante el auge del régimen nacionalsocialista, el autor presenta su primera "muestra" de este proyecto y en 1938 concluye el ensayo "El París del segundo Imperio en Baudelaire", en el cual aparece la figura del flâneur. Por último, en 1939, un año antes de su muerte, Benjamin publicó el ensayo "Sobre algunos motivos en Baudelaire" en la revista de investigación social (Zeitschrift für Sozialforschung) que dirigían Theodor Adorno y Max Horkheimer.

Tras el suicidio de Benjamin en septiembre de 1940, se encontraron varios fragmentos que contenían variantes o profundizaciones sobre la figura de Baudelaire y del flâneur. Varios de estos materiales aparecieron en la famosa edición de Rolf Tiedemann y Werner Schweppenhäusen del proyecto conocido como Libro de los pasajes (Konvolut J), así como en el volumen "Parque Central" (Zentralpark).

En "El París del segundo imperio en Baudelaire" (Benjamin 2014, pp. 67 y ss.), el autor rastrea la desastrosa situación económica de Baudelaire en el "mercado" literario de su tiempo a la vez que esboza varios elementos de la flânerie. Entre ellos está su condición de observador sosegado del paisaje urbano: "Lo sosegado de estas descripciones se adecua al hábito del flâneur, que acude al asfalto a "hacer botánica" (Benjamin 2014, p. 69). O su condición reflexiva pero superficial: "El flâneur se encuentra a sus anchas dentro de ese mundo [el de las galerías o pasajes], y así provee de su cronista y su filósofo 'al lugar preferido de los paseantes y los fumadores, el lugar de recreo de todos los pequeños oficios posibles [...] la agradable negligencia que es propia del flâneur" (Benjamin 2014, p. 75). O su condición de habitante de la calle: "De este modo, la calle se convierte en morada propia del flâneur, el cual se encuentra en casa entre fachadas lo mismo que el burgués entre cuatro paredes" (Benjamin 2014, p. 70). O su fascinación por las masas: "El desconocido es el flâneur. Así lo entendería Baudelaire cuando, en su ensayo sobre Guys, calificó al flâneur de 'l'homme des foulles' [hombre de multitudes]" (Benjamin 2014, p. 83).

La flânerie hace referencia, como mínimo, a dos dimensiones de análisis: la primera tiene que ver con la persona de Baudelaire y con su "personaje" autorreferencial, que también se presenta como una figura pseudoanónima, en tercera persona. La segunda da cuenta de la apropiación de Benjamin tanto de la figura del poeta como de su "personaje", para mostrar ciertas prácticas, actitudes y estrategias de supervivencia que el artista moderno desarrollaría frente al capitalismo industrial del siglo XIX. Es esta segunda acepción la que me interesa en el presente estudio, pues en ella hay varios elementos narrativos y filosóficos que coinciden con la figura del mestizo, según veremos más adelante.

Revista de Filosofía Diánoia, vol. 65, no. 85 (noviembre de 2020-abril de 2021) e-ISSN: 1870-4913 • DOI: https://doi.org/10.22201/iifs.18704913e.2020.85.1776 


\subsection{El flâneur y lo moderno}

Sin dejar de "ser" al mismo tiempo el personaje creado por Baudelaire y, de algún modo, también el propio Baudelaire, la noción de flâneur representa para Benjamin una clave hermenéutica para leer la modernidad a través de la práctica escritural del poeta francés, a quien Benjamin admiró toda su vida. Un elemento clave para entender esta situación del artista dentro de la sociedad moderna industrial es el concepto de mercancía, pues a través de ella el poeta se posesiona de la fantasmagoría y la ebriedad propia de las masas altocapitalistas. Dice Benjamin:

Y es que el flâneur es un abandonado en la multitud, compartiendo por tanto la situación de la mercancía. Esta particularidad no es consciente, mas no por ello influirá menos en él. Le penetra venturosamente al igual que un estupefaciente que sin duda le puede resarcir de humillaciones abundantes. Y esa ebriedad a la que el flâneur se entrega es la misma de la mercancía que arrastra el curso de los compradores. (Benjamin 2014, p. 91)

La mercancía se presenta en la vida del poeta-flâneur como una dimensión cada vez más invasiva de su existencia, al punto de confundirse con su situación vital en el mundo. Esta percepción de sí mismo como mercancía será, para Benjamin, el rasgo definitorio de Baudelaire y su flânerie. Es el elemento que atraviesa y da sentido a todas sus características. En el siglo XIX, apunta Benjamin, el artista burgués no ha cobrado completa consciencia de la alienación a la que se abocan todos los sujetos modernos debido a su servidumbre al capital. Sin embargo, a causa de sus circunstancias concretas, este artista (representado por Baudelaire) fundamenta su trabajo artístico en la enajenación de lo humano, que el hechizo de la mercancía subsume, absorbe y disuelve.

Frente al influjo de la mercancía, el artista, devenido en flâneur de la vida cotidiana, se ve obligado a "inventar" una manera de preservar su lugar en la sociedad como creador de goce estético al tiempo que sobrevive en el mundo de las mercancías. Esta estrategia está marcada, para Benjamin, por una "sensibilidad" estética que ve encanto y placer en lo deteriorado y decadente, gesto característico de la poesía baudeleriana. Por ello sostiene Benjamin:

Si en esta manera de gozar se quería llegar al virtuosismo, no podía rechazarse la empatía con la mercancía. Había que paladear esa empatía con el placer y zozobra derivada del sentimiento de su determinación en tanto

Revista de Filosofía Diánoia, vol. 65, no. 85 (noviembre de 2020-abril de 2021) e-ISSN: 1870-4913 • DOI: https://doi.org/10.22201/iifs.18704913e.2020.85.1776 
que clase. Al fin y al cabo, tenían que afrontarla con una forma de sensibilidad que incluso en lo deteriorado y lo podrido siguiera percibiendo los encantos. [...] A ella debía el goce habilitado en esta sociedad en cuanto medio desterrado de ella. (Benjamin 2014, p. 95)

Esta sensibilidad del el artista moderno se expresa en su flânerie, que se entiende como el vagabundeo y la fascinación casi hipnótica que ocasionan las masas modernas acechadas infatigablemente por la mercancía. En ese sentido, Benjamin atribuye a Baudelaire un "heroísmo", pues el poeta tiene la capacidad de interpretar y encarnar su época, signada por la irrealidad y la alienación capitalista.

Tal "heroísmo moderno", como apunta el profesor israelí Eli Friedlander, adopta una dimensión esencialmente teatral, pues se trata de recoger, a través de una "alegoría de sí mismo", el goce que la mercancía arrebata a lo humano (Friedlander 2012, p. 142). Ésta es la mayor tarea de su época en la medida en que pone en juego el sentido último de lo humano en el seno de la modernidad. Por ello el autor en el Libro de los pasajes señala que "para Baudelaire, nada hay en su siglo que se acerque más a la tarea del antiguo héroe, que darle forma a la modernidad" (Benjamin 2005, p. 330).

Por otra parte, la teatralidad del flâneur surge como respuesta a una crisis del arte por la alteración radical del significado de éste en la modernidad capitalista europea. Así, el artista moderno se afirma como una suerte de "actor de sí mismo" ya que, como dice Benjamin en Parque central, el flâneur desarrolla "en sí algo del mimo que debe interpretar el papel del 'poeta' ante un patio de butacas y una sociedad que ya no necesita al poeta auténtico, concediéndole sólo, todavía, un espacio de juego como mimo" (Benjamin 2014, p. 215).

Según esta lectura, el gran acierto de Baudelaire consiste en presentir antes que ningún otro artista el vacío en el que se disolvía el valor de todo arte (el valor de uso de la poesis humana) e ingeniar un mecanismo poético para expresar esa angustia a través de un procedimiento poético que privilegia la alegoría. Benjamin afirma que Baudelaire:

fue el primero en tomar consciencia, y del modo más rico en consecuencias, de que la burguesía estaba a punto de retirarle al poeta su misión. ¿Qué misión podía sustituirla? No había clase a la que pedirle una respuesta, así que lo mejor era extraerla del mercado y de sus crisis.

[...] Baudelaire se vio obligado a revindicar la dignidad del poeta en una sociedad que ya no disponía de ninguna dignidad que conferir. De ahí la bouffonerie de su conducta. (Benjamin 2014, p. 218) 
De este modo, frente a la subsunción del valor de uso por el valor que se valoriza a sí mismo, el poeta se vio obligado a imaginar una estrategia estética - que da cuenta de una actitud y de un comportamiento vitalpara preservar el sentido de su labor (algo similar a lo que Benjamin llamó "ruina" en su obra sobre el Trauerspiel) al tiempo que aceptaba la imposibilidad fatal de recuperarla del todo. La alegoría, con su amplitud semiótica y su flexibilidad metafórica, es la respuesta del flâneur. Se trata de una respuesta estética y a la vez existencial en la que Benjamin encuentra un modo de ser del sujeto, una suerte de paradigma del artista moderno frente al hecho capitalista. Esta respuesta es, pues, su flânerie.

\subsection{La alegoría en Benjamin}

En El origen del Trauerspiel, Benjamin describe un carácter inverso entre el principio del símbolo, propio del arte clásico, y la alegoría, característica del barroco (Benjamin 2010, p. 381). En el primer caso se produce una suerte de ascensión de las cosas hacia el terreno de la significación de lo uno y eterno (sin tiempo) y, en ese sentido, la imagen se vuelve portadora del significado. En el segundo caso el movimiento de significación se invierte, es decir, que lo uno se fragmenta en una constelación irregular de metáforas con el fin de volverse asequible en una narración que acaece a través de una sucesión temporal específica y concreta.

Como tropo literario, la alegoría se caracteriza por la proliferación incesante de metáforas dentro de una estructura narrativa. Esta proliferación tiene que ver también con una multiplicación de significados que, en su extremo, tiende al efecto paradójico de que un significante represente al mismo tiempo un significado y su contrario. Esta proliferación y ambigüedad provoca muchas veces una sensación de angustia frente a la ausencia de una atribución estable de significado para cada metáfora. Benjamin afirma además que la ambigüedad y la angustia representan bien la tensión dialéctica de lo contingente en el mundo natural (Benjamin 2010, p. 395). La alegoría se asocia de modo natural con el arte barroco, pues su estructura se acopla a varias de las características propias de esta corriente estética, como los múltiples juegos de significación, la ambigüedad omnipresente y los efectos estéticos escondidos entre pliegues y repliegues.

La alegoría sería, como se ha dicho arriba, una manera de "secularización" del símbolo; es decir, un modo de "rebajar" o "vulgarizar" el significado universal y eterno de éste para ponerlo al nivel de las narraciones cotidianas, contingentes y ambiguas.

Revista de Filosofía Diánoia, vol. 65, no. 85 (noviembre de 2020-abril de 2021) e-ISSN: 1870-4913 • DOI: https://doi.org/10.22201/iifs.18704913e.2020.85.1776 
La condición de sucesión temporal de la alegoría supone un movimiento dialéctico interior que da cuenta del "abismo" que se tiende entre la figuración y la idea; esto es, entre la representación y aquello que se representa. Para Benjamin, "la calma contemplativa con la que [la alegoría] se sumerge en el abismo entre el ser figurativo y el significar no tiene nada de la desinteresada suficiencia que se encuentra en la emparentada intención del signo" (Benjamin 2010, p. 381). Es esta dialéctica entre figuración y significación la que se manifiesta en la forma del drama barroco alemán o Trauerspiel.

Benjamin desarrolló estas ideas sobre la alegoría y el arte barroco en su trabajo seminal sobre el Trauerspiel hacia 1918, cuando intentaba capacitarse como catedrático. Más de una década después, el filósofo volvió a ellas, pero esta vez como insumos de sus proyectos filosóficos sobre París y Baudelaire, sobre todo para el monumental Libro de los pasajes. En estos textos de madurez, la alegoría se asocia con un concepto fundamental que Benjamin tomó de su nueva orientación teórica marxista: la mercancía.

\section{4. Alegoría y mercancía}

El joven Benjamin presentó la forma alegórica del Trauerspiel como producto de las épocas de conmoción y ruptura social cuya "sustancia" principal era el sufrimiento y cuya expresividad y dramatismo se manifiesta en la proliferación de significados ambiguos y paradójicos. Sobre esta base, el Benjamin maduro, ya convertido al marxismo, interpretó la sociedad industrial del siglo XIX europeo como una época trágica para la humanidad, una etapa histórica en la que los sujetos sociales sufren las agudas contradicciones del capitalismo y ven enajenada su libertad, disuelta en el hechizo de la mercancía.

El procedimiento alegórico se vuelve una estrategia fundamental para entender la fantasmagoría que ejerce la mercancía en la modernidad europea. A través de esta figura literaria, Benjamin encuentra una pista para vincular la poesía del Baudelaire con la estructura "económica" de la cultura moderna. Por ello, el profesor Friedlander afirma que "el entendimiento del proceso económico como una experiencia estructurante implicará [para Benjamin] esencialmente el análisis de la mercancía y su forma de expresión será alegórica" (Friedlander 2012, p. 153). Esta forma de expresión tendrá un lugar privilegiado en sus estudios sobre Baudelaire, pues en ellos analiza precisamente la configuración alegórica de la mercancía como aquello que transfigura al artículo de masas en lo "siempre de nuevo igual"; es decir, en la fan- 
tasmagoría que presenta como novedad aquello que manufactura como una más entre miles de copias.

La producción industrial capitalista tiende a ocultar la fragmentación del sujeto y la invasión de la mercancía en el mundo de la vida de los individuos. Sin embargo, el núcleo narrativo de la alegoría tiene la capacidad de poner en evidencia los desgarramientos, las contradicciones y la "disrupciones" encubiertas por la apariencia de estabilidad capitalista, pues aquello "a lo que se refiere la intención alegórica es separado de los contextos de la vida: y con ello es tan destruido como conservado. La alegoría se aferra a las ruinas, ofreciendo la imagen de la inquietud coagulada" (Benjamin 2014, p. 219). Así, la alegoría baudeleriana se aferra a las ruinas de libertad que va dejando el imperio de la mercancía $\mathrm{y}$, mediante su proliferación de metáforas, mantiene viva la imagen de esa libertad aunque no sea más que como ensoñación poética. En este sentido, Friedlander añade: "En contra de esta tendencia a fetichizar la mercancía, la expresión alegórica redescubre la disrupción debajo de la superficie de esta aureática apariencia de vida" (Friedlander 2012, p. 153).

De ahí que para Benjamin el mecanismo alegórico de la poesía de Baudelaire sea capaz de expresar al mismo tiempo: 1) las ruinas de lo humano en el capitalismo europeo y 2) la posibilidad de conservar esas ruinas bajo la forma de la obra de arte. El espacio de significación de la libertad, apunta Friedlander 2012 (p. 155), surge así del poder "avasallador" de la apariencia, el cual en último término "tiende a la disolución de la apariencia de la mercancía".

En medio del avance irresistible de la mercancía, Baudelaire - paradigma del flâneur - inventa un modo de expresión alegórica que podría interpretarse como un modo de resistencia de la libertad (o sus ruinas). Como dice Benjamin (en Friedlander 2012, p. 155): "Lo que resiste a la transfiguración mendaz del mundo de la mercancía es su distorsión en alegoría". Por ello, no hay que olvidar que: "Las alegorías son en el reino de los pensamientos lo que las ruinas en el reino de las cosas. De ahí el culto barroco a la ruina" (Benjamin 2010, p. 396).

A través de sus estudios sobre la alegoría, el pensador berlinés sugiere un vínculo entre los modos de expresión alegórica del barroco con el procedimiento alegórico propio del poeta moderno, para quien la alegoría es una estrategia de representación de la libertad como ruina; es decir, aquello que, aunque subsumido en la fantasmagoría de la mercancía, subsiste bajo la forma de la potencia estética de la expresión literaria. Ruinas en las que perviven las "imágenes del deseo" (BuckMorss 1995, p. 236) del siglo XIX en calidad de "escombros" que le toca

Revista de Filosofía Diánoia, vol. 65, no. 85 (noviembre de 2020-abril de 2021) e-ISSN: 1870-4913 • DOI: https://doi.org/10.22201/iifs.18704913e.2020.85.1776 
descifrar al presente. El hacer poético del flâneur aparece, entonces, como una alegorización de las "ruinas" de lo humano en las que, contra todo, persiste el impulso de la libertad.

\section{El mestizo latinoamericano}

\subsection{Mestizaje y sujeto social}

La primera vez que aparece el concepto de mestizaje en una obra publicada de Bolívar Echeverría es en el ensayo "La identidad evanescente" (1995), cuyo texto fue primero una conferencia para el Primer Encuentro Hispano-Mexicano de Ensayo y Literatura, celebrado en la Facultad de Filosofía y Letras de la UNAM en febrero de 1991. Allí Echeverría traslada sus nociones teóricas sobre la identidad y la cultura —que trabajó en el ensayo "La 'forma natural' de la reproducción social" (1984)hacia el "fenómeno" histórico concreto del mestizaje en las colonias españolas de América a partir del siglo XVI.

En "La identidad evanescente" el concepto de mestizaje no se refiere a una concepción histórica, pues significa un proceso de crisis constante de la subcodificación humana (identidad) en general respecto del código de signos animal. Tal identidad social, como cualquier organismo vivo - es decir, uno que se constituye a sí mismo a cada instante en su propia historicidad - sólo podía ponerse en crisis en la medida en que entra en contacto con "otro" sujeto. Este otro pondrá en juego valores de uso que representarán una necesaria interpelación de la "mismidad" del primero. Esta "negociación" de valores de uso supone una crisis infatigable de las "mismidades" que se encuentran en el "mercado" de las significaciones, de suerte que la actualización, perenne y siempre concreta, de una identidad implica una crisis del compromiso "arcaico" que, según Echeverría, cada identidad mantiene con el "principio" fundante de su socialidad.

Esta dialéctica entre identidad y cultura es el núcleo teórico a partir del cual Echeverría desarrolla conceptos esenciales como: 1) mestizaje, en cuanto momento dialéctico de confrontación, crisis y posterior "devoramiento" de las identidades; 2) ethos histórico (como una forma de conexión de cada presente histórico con "esos compromisos sucesivos que se han venido acumulando en la determinación de lo humano como una realidad concreta e identificada" (Echeverría 2006, p. 201); 3) cuádruple ethos de modernidad como "estrategia" de los sujetos sociales frente a las violentas contradicciones que introduce la modernidad capitalista en la vida cotidiana de tales sujetos), y 4) ethos barroco; es decir, 
la estrategia específica que reivindica "ambigua y paradójicamente" el valor de uso frente al valor a través de los elementos característicos del barroco ya no considerado sólo como una corriente artística, sino como un comportamiento civilizatorio.

En sus trabajos posteriores (1998, 2006, 2010a [póstumo]), Echeverría amplía su entendimiento sobre el "mestizaje". Ya no lo considera únicamente como una instancia teórica de la reproducción de toda identidad humana, sino que lo emplea para identificar un proceso histórico de combinación y "devoramiento" de identidades a escala continental producido en América a partir del siglo XVI; un proceso establecido, además, como "política cultural" por la contrarreforma jesuita y la corona española.

En este sentido, el interés filosófico de Echeverría se centra sobre todo en el mestizaje de los indios que habitaron las primeras urbes modernas americanas, pues éste se prestaba muy bien para explicar el ethos barroco. El escenario de crisis civilizatoria que reinaba en las ciudades americanas durante los primeros siglos de la colonia implicaba la necesidad de una solución civilizatoria urgente para evitar la barbarie general. Por eso dirá el profesor Isaac García Venegas:

De este modo, Bolívar Echeverría atribuye al mestizaje cultural un papel protagónico en la conformación del ethos barroco y en su resistencia a las exigencias propias de la modernidad capitalista. Aunque puede decirse que su comprensión del mestizaje cultural como "codigofagia" es propio de la cultura misma y del modo de transformación de cualquier cultura, el punto central, y a la vez radical de esta comprensión, reside en que identifica este proceso en un escenario de crisis y devastación que exige una reconstrucción social desesperada, por un lado, y por el otro, que atribuye a los indígenas urbanos, esto es, a los sectores sociales más bajos, la estrategia espontánea del mestizaje cultural para sobrevivir, reconstruir y hasta donde es posible vivir. (García Venegas 2014, p. 254)

Por lo tanto, en lo que sigue de este trabajo me referiré al "mestizaje" y al "mestizo" como conceptos que Echeverría emplea para pensar la modernidad en América Latina a través de sus diferentes "estratos de formación", sobre todo en el periodo que el autor llamó el "largo siglo XVII" para nombrar el lapso entre el siglo XVII y los mediados del siglo XVIII. Llamaré "mestizo" al sujeto social que, aunque no trabajado como una individualidad, como Benjamin hace con el flâneur, sí puede rastrearse como protagonista del proceso concreto de mestizaje en América Latina. Para Echeverría, el mestizo corresponderá más a una 
estrategia estilística que a una personificación continua de una figura concreta. Sin embargo, como veremos más adelante, el núcleo argumental de ambas nociones es una estrategia de supervivencia frente a las contradicciones de la modernidad capitalista a través de una alegoría barroca.

\subsection{Flânerie y mestizaje, alegorías modernas}

Se podría pensar que hay al menos dos órdenes de ideas que identifican al flâneur con el mestizo latinoamericano. Primero está el hecho de que ambas figuras se vinculan con visiones catastróficas de la vida producidas por una "amenaza" de proporciones inmensas y que tocan un núcleo íntimo de una sujetidad moderna. En segundo término, tanto el flâneur como el mestizo responden a tal "situación de peligro" con una "alegorización" de sí mismos y de su entorno histórico.

Para Benjamin la alegoría es un elemento axial de su noción de barroco. La alegoría representa la respuesta de un sujeto social cuya humanidad está amenazada por una experiencia trágica de la historia. Friedlander añade que la alegoría surge en el barroco en la medida en que "se opone a la proyectada completitud que aparece en la expresión simbólica" (Friedlander 2012, p. 152). De modo que, según esta lectura, el concepto de modernidad y el de alegoría aparecerían vinculados dialécticamente en la experiencia de un sujeto social cuya vida se siente en peligro, como aquella que el flâneur experimentaba en el siglo XIX en pleno auge del capitalismo. La capacidad de expresar esta visión constituye la "sabiduría" del artista, su talento consiste en alegorizar lo perdido y, con ello, conservar su imagen.

Para Friedlander, la construcción de Benjamin del flâneur obedece a la intención de relacionar la tarea de Baudelaire (dar forma, modelar, la modernidad) con la forma del Trauerspiel (Friedlander 2012, p. 261). De hecho, Benjamin reconoció la conexión entre barroco y flânerie como dos fenómenos derivados de una misma reacción alegórica frente al avance de la mercancía. En palabras Benjamin:

Relación entre mercancía y alegoría: el "valor", como espejo ustorio natural de la apariencia histórica, desborda el "significado". Difícilmente se puede disipar su apariencia, que es, por otra parte, la más reciente. El carácter fetichista de la mercancía todavía estaba en el barroco relativamente poco desarrollado. La mercancía tampoco había estampado tan profundamente su estigma - la proletarización de los productores - en el proceso productivo. Por eso la intuición alegórica del siglo diecisiete crea estilo, pero ya no la del diecinueve. Baudelaire, en cuanto alegórico, se quedó 
aislado. Intentó reconducir la experiencia de la mercancía a la experiencia alegórica. Esto tenía que fracasar, y con ello se evidenció que la inflexibilidad de su punto de partida quedó desbordada por la inflexibilidad de la realidad. De ahí que cierto tono patológico o sádico de su obra se deba a que erró el blanco — la realidad-, pero sólo por la mínima. (Benjamin 2005, p. 345)

Benjamin ofreció en su trabajo sobre el drama barroco alemán toda una "teoría cultural" que relacionaba la alegoría con una época trágica en la que la vida (y su forma natural, es decir, su valor de uso) estaba marcada por una amenaza de muerte. De modo similar, el siglo XIX es, para Benjamin, una época profundamente desdichada, en la que el valor de uso se subsume en el influjo de la mercancía. Frente a ese estado de desesperanza civilizatoria, el flâneur "inventa" una sensibilidad que, a través de la alegoría, será capaz de: 1) dar cuenta de aquella situación alterada de lo humano en la modernidad y 2) a través de ese reconocimiento preservar el "sentido" de lo poético (el valor de uso estético) a través de una suerte de teatralización de sí mismo y del papel del arte en esa nueva sociedad.

En términos abstractos, esta descripción guarda una similitud fundamental con la estrategia civilizatoria "inventada" por las poblaciones mestizas que describe Echeverría. La "sensibilidad" social que pone en juego el mestizo implica una toma de postura frente a la tragedia de la destrucción de las civilizaciones arcaicas y la indefensión cultural de los europeos en América, desconectados de la metrópoli y aislados de su influjo. La estrategia de los indios urbanos será entonces "recrear" en términos alegóricos la identidad de los españoles para preservar la vida (es decir su valor de uso) frente a la amenaza de la barbarie generalizada. A través de este proceso de recreación alegórica, el mestizo se convierte en una especie de actor de sí mismo, un personaje que convierte su mundo de vida en una narración alegórica en la que proliferan signos equívocos o incluso contradictorios.

Igual que con el flâneur, la máscara del mestizo no es un signo de frivolidad, sino una necesidad insustituible de la naturaleza de su tarea (Friedlander 2012, p. 216). Ambos "actúan" en los márgenes de la sociedad, emplean materiales "desechados" por los sujetos sociales hegemónicos, los reelaboran y recrean a través de una mirada que descubre un valor en lo descartado, lo olvidado, lo marchito. Benjamin decía que el héroe moderno - es decir, el flâneur y, añadiría, el mestizo- estaba prefigurado en la figura del trapero, pues realiza su tarea con los "desechos y desperdicios de la gran ciudad" (Benjamin 2005, p. 374). El mes-

Revista de Filosofía Diánoia, vol. 65, no. 85 (noviembre de 2020-abril de 2021) e-ISSN: 1870-4913 • DOI: https://doi.org/10.22201/iifs.18704913e.2020.85.1776 
tizo —según Echeverría 2010a, p. 183- surge en las zonas periféricas de las grandes ciudades coloniales como un sujeto que usa los objetos y los signos que los criollos descartan como bajos o inauténticos para elaborar una versión propia del código europeo. A través de la alegoría como comportamiento social, este proceso de "imitación" crea profusamente significados, materiales, imágenes, ideas, comportamientos que pronto "sobrepasan" sus moldes europeos.

El sujeto alegórico — tanto en el siglo XVII como en el XIX- establece una relación con los objetos contraria a la del coleccionista. Como apunta Benjamin, este sujeto no pretende conocer las cosas, penetrarlas con el entendimiento, sino que "las desprende de su entorno, dejando desde el principio a su melancolía iluminar su significado" (Benjamin 2005, p. 222). Las cosas se presentan como un catálogo de significantes monádicos, por así llamarlos, que siempre pueden tener un significado y su contrario, pues están expuestos al arbitrio de la imaginación nostálgica que junta imágenes de modo aleatorio y aglutinante para producir sentidos en la vida cotidiana. Es un procedimiento contrario al del símbolo, cuyo movimiento "eleva" lo múltiple hacia la unidad del significado.

Frente a dos situaciones análogas, ambas de inmenso peligro, en sendas etapas de puesta en marcha de la modernidad, tanto el flâneur como el mestizo responden a través de una "estrategia alegórica" que deviene en una "teatralización" tanto de sí mismos, en su calidad de sujetos sociales, como de sus mundos de la vida. Frente a una pérdida de consistencia de la realidad —en el siglo XVII por la amenaza civilizatoria producida por la destrucción de las identidades indígenas; en el XIX por la invasión irresistible de la mercancía en la vida cotidianaambos sujetos encuentran una manera de sobrevivir a través de una alegorización barroca que absorbe, al tiempo que trasciende dialécticamente, una contradicción insoportable.

Dice Benjamin que, para "el flâneur, su ciudad —aunque haya nacido en ella, como Baudelaire- no es ya su patria. Representa un escenario" (Benjamin 2005, p. 345). Esta "condición teatral" ofrece la clave para entender la flânerie del siglo XIX como reacción frente al vaciamiento de sentido que introdujo la modernidad capitalista. Según Friedlander:

Es la teatralidad del mundo que Benjamin diagnostica en el barroco la que podría explicar mejor el predicamento de Baudelaire. El sentido del mundo como una escena autoencerrada tiene que entenderse en relación con un sentido de su ser vaciado de significado. (Friedlander 2012, p. 143) 
Por su parte, Echeverría ha subrayado la teatralidad como una de las principales características de la estrategia barroca del sujeto mestizo frente a la modernidad. No sólo eso. Para nuestro autor, los indios urbanos latinoamericanos del siglo XVII convirtieron todo el conjunto de su realidad social en una "puesta en escena absoluta" (messinscena assoluta) para reconstruir una sujetidad moderna que se niega a resignarse frente a la destrucción de su valor de uso.

\subsection{El flâneur y el mestizo, paradigmas de sujetidad barroca}

Hasta aquí caractericé en forma somera las figuras del flâneur y del mestizo como una suerte de representantes de dos respuestas frente a sendas etapas de la modernidad capitalista. Ahora quisiera articularlas, a modo de conclusión, y conectarlas con la noción de paradigma (Agamben 2010a).

Friedlander formula una pregunta acerca de la relación entre Baudelaire y la obra de Benjamin que podría funcionar también para las figuras que, en su caracterización del mestizo, Echeverría trabajó a partir de personajes individuales como la indígena Malitzin (Echeverría 1998), la virgen de Guadalupe o el caballero ficticio Alonso Quijano (Echeverría 2010a):

La misma presencia de Baudelaire en un trabajo como los Pasajes, como una figura que puede plasmar los elementos filosóficos decisivos de ese proyecto, plantea cuestiones importantes: ¿Cómo funciona un nombre propio al presentar la extensión del significado de la historia? ¿Podemos hablar en la modernidad de individuos representativos y cuál es su relación con el colectivo y con los tiempos? (Friedlander 2012, p. 140)

Pensar esta pregunta ampliándola a la relación del flâneur y el mestizo con la modernidad supone pensarlos como "paradigmas", según ha entendido esta categoría Agamben. Para el filósofo italiano, un paradigma puede concebirse como "un objeto singular que, valiendo para todos los otros de la misma clase, define la inteligibilidad del conjunto del que forma parte y que, al mismo tiempo, constituye" (Agamben 2010a, p. 22). En el caso del mestizo y del flâneur, la "inteligibilidad" que se pone en juego se vincula con una "actitud" de resistencia frente a la amenaza que la modernidad introduce respecto de la "forma natural" de su vida social, es decir, los valores de uso de su vida cotidiana.

Con la ampliación de su idea sobre el paradigma, Agamben afirma que el "método" que empleó en sus trabajos sobre el homo sacer y el

Revista de Filosofía Diánoia, vol. 65, no. 85 (noviembre de 2020-abril de 2021) e-ISSN: 1870-4913 • DOI: https://doi.org/10.22201/iifs.18704913e.2020.85.1776 
muselmann tenía "por objetivo hacer inteligible una serie de fenómenos cuyo parentesco se le había escapado o podía escapar a la mirada del historiador" (Agamben 2010a, p. 41). Así, sugiere que la singularidad del paradigma no es una característica que se presenta de suyo, "por sí misma", en el relato histórico. Más bien, parecería construida por la interpretación de una "mirada" capaz de extraer un fenómeno "característico" para confrontarlo con el tipo de fenómenos al que pertenece. El paradigma no "manifiesta" una semejanza preexistente, sino que la "crea" mediante la exploración de "parentescos" y simetrías, así como con la exhumación de zonas desatendidas por las narrativas históricas hegemónicas. La construcción heurística de esa singularidad lograría mostrar junto a sí ( para-deíknymi) "su propia inteligibilidad y, a su vez, la de clase que constituye". De ese modo, a través de la caracterización del fenómeno extraído se perfila también la "totalidad" de fenómenos de la cual es paradigma.

Tanto Benjamin como Echeverría erigen la singularidad del mestizo y del flâneur mediante el empleo de la alegoría como una estrategia de aceptar la destrucción y al mismo tiempo mantener ciertos valores de uso. En el caso de las identidades arcaicas americanas se trata de la destrucción total de ciertas civilizaciones debido al embate de la modernidad europea del siglo XVII, y en el caso de las identidades sociales del mundo altocapitalista del siglo XIX una destrucción de la libertad debido al influjo hechizante de la mercancía. Esta singularidad pone en relación ambas figuras con un tipo de fenómenos que se identifican con una actitud, con un ethos moderno, que Echeverría caracterizó como barroco.

Al explorar los sentidos que los sujetos sociales han empleado para enfrentar las contradicciones del capitalismo, Benjamin y Echeverría encontraron sendas "maneras" de sujetidad alegórica cuya inteligibilidad interpretaron a través de los elementos del barroco. Se diría que el flâneur y el mestizo son, entonces, paradigmas de una sujetidad barroca; esto es, de una sujetidad que, apelando a cierta voluntad de forma -que representan tanto el Trauerspiel alemán como la "puesta en escena absoluta" latinoamericana-, privilegia el valor de uso de su vida cotidiana frente a la destrucción de la libertad y el ejercicio de lo político.

Según la argumentación de Agamben, la singularidad y la inteligibilidad de estas sujetidades barrocas se produce a través de un "cruce" de su sincronía y su diacronía con otros fenómenos. No se trata de mostrar -o no solamente- la pertenencia del flâneur o el mestizo a sus "continuidades" históricas, sino más bien de extraerlos de esa "continuidad" 
y considerarlos en relación con su "principio" (esto es, con su arché o la inteligibilidad de su historicidad), lo cual se relaciona tanto con el momento histórico investigado como con el presente del investigador. De acuerdo con Agamben:

Pero la arché que éstas alcanzan [sus investigaciones] - y esto vale, quizá, para toda investigación histórica - no es un origen presupuesto en el tiempo, sino que, al situarse en el cruce de diacronía y sincronía, vuelve inteligible no menos el presente del investigador que el pasado de su objeto. (Agamben 2010a, p. 41)

Tanto Benjamin como Echeverría elaboran proyectos filosóficos que intentan palpar "a contrapelo" el pelaje de la historia. Sus paradigmas de sujetidad suponen casos en los que se puede percibir una "discontinuidad" respecto de las narraciones oficiales de la modernidad. Proyectadas ambas en "momentos de peligro" - el ascenso nacionalsocialista alemán y el colapso del socialismo "real" - las dos figuras paradigmáticas dan cuenta de sendos proyectos de sentido que "iluminan" el presente problemático de sus autores. Pero, puesto que se sitúan en ese instante de peligro en el que "los vencedores no han dejado de vencer", el flâneur y el mestizo representan formas de una sujetidad barroca que también afectan este presente, el aquí y ahora, y abren un horizonte de inteligibilidad para una resistencia alegórica que reivindique el valor de uso en el siglo XXI.

De ahí que se pueda pensar en el mestizo y el flâneur como exemplum en el sentido de Agamben 2010a (p. 24), porque su ejemplaridad consiste en crear "sentidos" a través de un "nuevo conjunto inteligible y un nuevo contexto problemático" de materiales obviados por la narración histórica. En el caso del flâneur, la alegoría, el Trauerspiel, la mercancía, o la teoría literaria; en el del mestizo, la semiosis social, el mestizaje, la identidad, el ethos barroco.

Para concluir, valdría apuntar que, para Agamben, la naturaleza de la inteligibilidad paradigmática tiene un carácter "ontológico" referido al "ser" de los fenómenos y no a "una relación cognitiva entre un sujeto y un objeto". Sin embargo, en los términos del presente estudio, esta frase sólo podría tener sentido siempre que se entienda "ontología" en el sentido de Echeverría 1998 (pp. 153 y ss.), para quien la única condición de "ser" de lo humano se da por y en el proceso de reproducción social.

La inteligibilidad paradigmática del flâneur y del mestizo es ontológica sólo en la medida en que es histórica. Al mostrarse, ambas "ilumi-

Revista de Filosofía Diánoia, vol. 65, no. 85 (noviembre de 2020-abril de 2021) e-ISSN: 1870-4913 • DOI: https://doi.org/10.22201/iifs.18704913e.2020.85.1776 
nan" (en el sentido benjaminiano) la conexión entre sus singularidades (alegóricas) y su arjé (barroco) en un "relámpago" de sentido frente a los "instantes" de peligro que la modernidad capitalista no ha dejado de introducir en todos los aspectos de la vida social.

\section{Referencias bibliográficas}

Agamben, Giorgio, 2010a, Infancia e historia. Destrucción de la experiencia y origen de la historia, trad. Silvio Mattoni, Adriana Hidalgo, Buenos Aires.

Agamben, Giorgio, 2010b, Signatura rerum. Sobre el método, trad. Flavia Costa y Mercedes Ruvituso, Barcelona, Anagrama.

Arismendi, Luis (comp.), 2014, Bolívar Echeverría. Trascendencia e impacto para América Latina, Instituto Nacional de Altos Estudios Nacionales, Quito.

Benjamin, Walter, 2005, El libro de los pasajes, trad. Isidro Herrera Baquero, Luis Fernández Castañeda y Fernando Guerrero, Akal, Madrid.

Benjamin, Walter, 2008, Tesis sobre la historia y otros fragmentos, intr. y trad. Bolívar Echeverría, UnAm/Ítaca, México.

Benjamin, Walter, 2010, El origen del Trauerspiel, tomo I, en Obras, Abada, Madrid.

Benjamin, Walter, 2014, Baudelaire, ed. José Manuel Cuesta Abad, Abada, Madrid.

Buck-Morss, Susan, 1995 [1989], Dialéctica de la mirada. Walter Benjamin y el proyecto de los Pasajes, trad. Nora Rabotnikof, Visor, Madrid.

Campuzano Arteta, Álvaro, 2020, "Bolívar Echeverría: traductor de Walter Benjamin”, Acta Poética, vol. 41, no. 1, pp. 91-113, <https://doi.org/10.19130/ iifl.ap.2020.1.867>.

Chiampi, Irlemar, 2000, Barroco y modernidad, Fondo de Cultura Económica, México.

Didi-Huberman, Georges, 2012, Supervivencia de las luciérnagas, trad. Juan Calatrava, Abada, Madrid.

Echeverría, Bolívar, 1984, "La 'forma natural' de la reproducción social", Cuadernos Políticos, no. 41, pp. 33-46.

Echeverría, Bolívar, 1986, El discurso crítico de Marx, Era, México.

Echeverría, Bolívar, 1997, Las ilusiones de la modernidad, Universidad Nacional Autónoma de México/El Equilibrista, México [1a. ed.: 1995].

Echeverría, Bolívar, 1998, Valor de uso y utopía, Siglo XXI, México.

Echeverría, Bolívar, 1996, "El ethos barroco", Debate Feminista, no. 13, pp. 6787, disponible en <https://www.jstor.org/stable/42624321>, <https://doi. org/10.22201/cieg.2594066xe.1996.13.291>.

Echeverría, Bolívar, 2000, La modernidad de lo barroco, Era, México.

Echeverría, Bolívar, 2001, Definición de la cultura, Ítaca/Universidad Nacional Autónoma de México, México.

Revista de Filosofía Diánoia, vol. 65, no. 85 (noviembre de 2020-abril de 2021) e-ISSN: 1870-4913 • DOI: https://doi.org/10.22201/iifs.18704913e.2020.85.1776 
Echeverría, Bolívar (comp.), 2005, La mirada del ángel. En torno a las tesis sobre la historia de Walter Benjamin, Facultad de Filosofía y Letras-UNAM/Era, México.

Echeverría, Bolívar, 2006, Vuelta de siglo, Era, México.

Echeverría, Bolívar, 2010a, Modernidad y blanquitud, Era, México.

Echeverría, Bolívar, 2010b, Siete aproximaciones a Walter Benjamin, Desde Abajo, Bogotá.

Echeverría, Bolívar y Horst Kurnitzky, 1993, Conversaciones sobre lo barroco, Universidad Nacional Autónoma de México, México.

Friedlander, Eli, 2008, "The Measure of the Contingent: Walter Benjamin's Dialectical Image", Boundary 2, vol. 3, no. 35, pp. 1-26, <https://doi.org/10. 1215/01903659-2008-010>.

Friedlander, Eli, 2012, Walter Benjamin. A Philosophical Portrait, Harvard University Press, Cambridge, <https://doi.org/10.4159/harvard.978067406 3020>.

Fuentes, Diana, "Bolívar Echeverría Andrade (1941-2010)", Enciclopedia Electrónica de la Filosofía Mexicana, disponible en <http://dcsh.izt.uam.mx/cen doc/cefilibe/images/banners/enciclopedia/Diccionario/Autores/Filosofos Mexicanos/Echeverria_Bolivar.pdf>.

Gandler, Stefan, 2007, Marxismo crítico en México: Adolfo Sánchez Vásquez y Bolívar Echeverría, Universidad Nacional Autónoma de México/Universidad Autónoma de Querétaro/Fondo de Cultura Económica, México.

García Barrios, Marco, 2012, "Sobre el concepto de 'cultura política' en Bolívar Echeverría”, Íconos, no. 43, pp. 33-46, <https://doi.org/10.17141/iconos. 43.2012.347>.

García Venegas, Isaac, 2014, "De mestizaje a mestizaje: notas sobre el mestizaje cultural y el ethos barroco de Bolívar Echeverría", en Luis Arizmendi, Julio Peña y Lillo E. Eleder Piñeiro (coords.), Bolívar Echeverría. Ttrascendencia e impacto para América Latina en el siglo XXI, Instituto de Altos Estudios Nacionales, Quito.

Oliva Mendoza, Carlos, 2013, Semiótica y capitalismo. Ensayos sobre la obra de Bolivar Echeverría, Ítaca, México.

Sánchez Prado, Ignacio, 2010, "Reading Benjamin in Mexico. Bolívar Echeverría and The Tasks of Latin American Philosophy", Discourse, vol. 1, no. 32, pp. 37-65, disponible en <http://www.jstor.org/stable/41389830>.

Sigüenza, Javier, 2011, "Modernidad, ethos barroco, revolución y autonomía. Una entrevista con el filósofo Bolívar Echeverría". Crítica y Emancipación, vol. III, no. 5, pp. 79-89.

Recibido el 9 de julio de 2019; revisado el 2 de abril de 2020; aceptado el 17 de mayo de 2020. 